\title{
An evaluation of statistical software for research and instruction
}

\author{
DARRELL L. BUTLER \\ Ball State University, Muncie, Indiana \\ and \\ DOUGLAS B. EAMON \\ University of Houston-Clear Lake, Houston, Texas
}

\begin{abstract}
A variety of microcomputer statistics packages were evaluated. The packages were compared on a number of dimensions, including error handling, documentation, statistical capability, and accuracy. Results indicated that there are some very good packages available both for instruction and for analyzing research data. In general, the microcomputer packages were easier to learn and to use than were mainframe packages. Furthermore, output of mainframe packages was found to be less accurate than output of some of the microcomputer packages.
\end{abstract}

Many psychologists use statistical programs to analyze research data or to teach statistics, and many are interested in using computer software for these purposes (e.g., Butler, 1984; Butler \& Kring, 1984). The present paper provides some program descriptions, benchmarks, and evaluations of a wide variety of marketed statistical programs that may be useful in research and/or instruction.

This review differs in several respects from other recent reviews of statistical programs (e.g., Carpenter, Deloria, \& Morganstein, 1984; Eamon, 1983; Francis, 1983; also see Wilson, 1983). First, the software evaluation was done by undergraduates as well as by a professional psychologist. Students were not used in other evaluations of programs. Second, this review is more recent and includes some changes in reported software as well as some new programs. Finally, the present evaluation places more emphasis on the apparent audience of a program. Other reviews typically have been directed to professional users only.

\section{PROCEDURE}

Software vendors were contacted in June and again in August or September 1984, and were asked to supply review copies of the most recent versions of their statistical programs. When appropriate, vendors were asked to supply versions that could run on an Apple II series computer, but they were also informed that we would review programs for other machines, such as the IBM PC. A list of vendors who responded is given in Table 1, along with program names, prices, and addresses. One other source of software was included in this evaluation, the major soft-

Send requests for reprints to Darrell L. Butler, Department of Psychology, Ball State University, Muncie, IN 47306. ware packages available on the VAX computers at Ball State University: BMDP, SPSSx, SCSS, and MINITAB. Versions of these programs are widely available and are used here as points of reference to judge the strengths and weaknesses of the microcomputer packages. Although there are many programs distributed by individuals (e.g., see Academic Computer Center of Gettysburg College, 1984, and Eamon, 1983), none are included in the present review. This choice was made because these programs are typically not well documented and sometimes contain bugs (Cline, 1972).

There were 11 reviewers-a professional academic psychologist and 10 undergraduates. The students were obtained by advertising in psychology courses. All students had completed a 10 -week course in elementary statistics with a passing grade. Some effort was made to ensure that students differed substantially in overall grade-point average (GPA) and in statistical sophistication. Each undergraduate was paid $\$ 3.35$ per hour for about $10 \mathrm{~h}$ of work per week during the fall quarter.

A student worked with one software package each week (approximately) in our supervised microcomputer laboratory. However, the student was given no extra help from faculty and had to rely on manuals and other available students to solve problems. This procedure provided a sensitive measure of ease of program use, an acknowledged problem when educators use mainframe statistical packages such as SPSS (see Thisted, 1979).

All students were given the same assignment for all programs. They were supplied with two groups of data (A and B), each containing nine data sets. The first data set in Group A involved the integers 1 through 9. The other data sets in Group A were created by algebraically altering the first data set along the lines suggested by Longley (1967). Longley suggested that accuracy of programs be tested by adding $100,1,000, \ldots$ to each datum and 
Table 1

Software Products, Prices, and Vendors

\begin{tabular}{|c|c|}
\hline Program (Price) & Vendor and Address \\
\hline \multicolumn{2}{|c|}{ Apple II Programs } \\
\hline $\begin{array}{c}\text { A-Stat }(\$ 200) \\
\text { v83.1 }\end{array}$ & $\begin{array}{l}\text { Rosen Grandon Associates } \\
7807 \text { Whittier Street } \\
\text { Tampa, FL } 33617 \\
\text { (813)985-4911 }\end{array}$ \\
\hline $\begin{array}{c}\text { Daisy }(\$ 200) \\
\text { v2.2 }\end{array}$ & $\begin{array}{l}\text { Rainbow Computing, Inc. } \\
8811 \text { Amigo Avenue } \\
\text { Northridge, CA } 91324 \\
(213) 349-0300 \text { and }(800) 423-5441\end{array}$ \\
\hline $\begin{array}{c}\text { ELF }(\$ 200) \\
v 5.0\end{array}$ & $\begin{array}{l}\text { The Winchendon Group } \\
3907 \text { Lakota Road } \\
\text { P.O.Box 10339 } \\
\text { Alexandria, VA } 22310 \\
\text { (703)960-2587 }\end{array}$ \\
\hline $\begin{array}{l}\text { HSD ANOVA II (\$150) } \\
\quad \mathrm{v} 1.1\end{array}$ & $\begin{array}{l}\text { Human Systems Dynamics } \\
9010 \text { Reseda Boulevard, Suite } 222 \\
\text { Northridge, CA } 91324 \\
(213) 993-8536 \text { and }(800) 451-3030\end{array}$ \\
\hline Keystat $(\$ 50 / \$ 10)^{\mathrm{a}}$ & $\begin{array}{l}\text { Oakleaf Systems } \\
\text { P.O. Box } 472 \\
\text { Decorah, IA } 52107\end{array}$ \\
\hline Peachtree Statistics $(\$ 30)$ & $\begin{array}{l}\text { Peachtree Software } \\
\text { 3445 Peachtree Road N.E. } \\
\text { Atlanta, GA } 30326 \\
(800) 554-8900\end{array}$ \\
\hline $\begin{array}{l}\text { Speedstat } \\
\text { (Vol. 1, \$249) } \\
\text { (Vol. 2, \$299) }\end{array}$ & $\begin{array}{l}\text { Softcorp International } \\
229 \text { Huber Village Boulevard } \\
\text { Westerville, OH } 43081 \\
\text { (800)543-1350 }\end{array}$ \\
\hline $\begin{array}{l}\text { STAN }(\$ 250) \\
\quad v 1.2\end{array}$ & $\begin{array}{l}\text { Statistical Consultants } \\
\text { 462 East High Street } \\
\text { Lexington, KY } 40508 \\
(606) 252-3890\end{array}$ \\
\hline Statmaster $(\$ 200 / \$ 24)^{b}$ & $\begin{array}{l}\text { Teri L. Bragg } \\
\text { College Division } \\
\text { Little, Brown and Company } \\
34 \text { Beacon Street } \\
\text { Boston, MA } 02106\end{array}$ \\
\hline $\begin{array}{l}\text { SYSTAT (\$495) } \\
\quad \text { v1.3 }\end{array}$ & $\begin{array}{l}\text { SYSTAT, Inc. } \\
603 \text { Main Street } \\
\text { Evanston, IL } 60202 \\
(312) 864-5670\end{array}$ \\
\hline Stat. and Prob. $(\$ 95)^{c}$ & $\begin{array}{l}\text { COMPress } \\
\text { P.O. Box } 102 \\
\text { Wentworth, NH } 03282 \\
(603) 764-5831\end{array}$ \\
\hline USTATS $(\$ 100)$ & $\begin{array}{l}\text { Wm. C. Brown Publishers } \\
5712 \text { Odana Road } \\
\text { Madison, WI } 53719\end{array}$ \\
\hline & $(608) 273-0040$ \\
\hline \multicolumn{2}{|c|}{ IBM PC Programs } \\
\hline $\begin{array}{l}\text { MICROSTAT (\$325) } \\
\quad \text { v4.1 }\end{array}$ & $\begin{array}{l}\text { Ecosoft, Inc. } \\
6413 \text { North College Avenue } \\
\text { Indianapolis, IN } 46220 \\
(317) 255-6476\end{array}$ \\
\hline $\begin{array}{l}\text { Number Cruncher }(\$ 200) \\
\quad \text { v4.1 }\end{array}$ & $\begin{array}{l}\text { Statistical Systems } \\
865 \text { East } 400 \text { North } \\
\text { Kaysville, UT } 84037 \\
\text { (801)546-0445 }\end{array}$ \\
\hline $\begin{array}{l}\text { NWA Statpak (\$495) } \\
\quad \text { v3.1 }\end{array}$ & $\begin{array}{l}\text { Northwest Analytical, Inc. } \\
520 \text { N.W. Dacis } \\
\text { Portland, OR } 97209 \\
(503) 224-7727\end{array}$ \\
\hline
\end{tabular}

Statpac (\$400)

Trajectories $(\$ 495)^{\mathrm{d}}$ v4.0

\author{
Walonick Associates \\ 5625 Girard Avenue South \\ Minneapolis, MN 55419 \\ (612)866-9022 \\ DBI Software \\ One Energy Place \\ 5805 East Pickard Road \\ Mt. Pleasant, MI $\mathbf{4 8 8 5 8}$
}

(800)221-3791

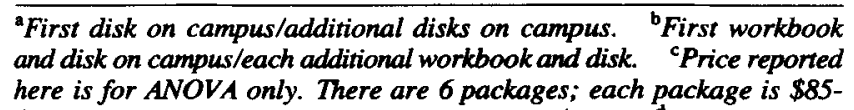
$\$ 95$, or one complete set can be obtained for \$450. ${ }^{\text {d Formerly SPS. }}$

rechecking program output. For our purposes, a slightly tougher standard was used. Eight other data sets were created by adding $90,900,9,000, \ldots$, or $900,000,000$ to each number in the original data set. The data sets in Group B were slight variations of the nine sets in Group A; one number in a Group A data set was changed to create an equivalent Group B data set. These changes made the moments of the data sets in Group B different from the data sets in Group A.

Student evaluators were asked to run independent statistical group $t$ tests between the first data set in Group A (the integers 1-9) and each of the other data sets. Then they were asked to run one-way, independent group analyses of variance (ANOVA). They were to run a simple two-group analysis (using 1-9 vs. 91-99), and then increase the complexity of the analysis by adding in the data sets having more digits per number. As a final step in formal evaluation, students were asked to run correlations between the original data set and all the others. Students were also encouraged to try to solve problems in their statistics books and to try out other capabilities of the programs. For example, several of the programs contained chi-square statistics, and students were encouraged to try some of these routines.

Each student met with the first author of this paper once each week to discuss the strengths and weaknesses of the program used during the previous week. In addition, the students supplied computer-printed and handwritten records of their interactions with the programs. These were studied (usually in the students' presence) to determine the ways in which the programs handled mistakes by the students, to determine whether vocabulary problems were creating difficulties for the students, and to determine the accuracy of the programs' output.

In addition to these student tests, the first author ran a number of checks on the flexibility and strength of the editors and analysis routines. These checks varied among programs because there were large differences in abilities of the software. Also, the manuals were studied in detail, and an attempt was made to compute "readability indexes" (e.g., Kincaid, Fishburne, Rogers, \& Chissom, 1975). Unfortunately, such indexes do not work well on manuals such as these. 


\section{TYPES OF PROGRAMS}

From the point of view of the user, there are three different apparent audiences of statistical programs. At one extreme are professional users who need programs that can analyze a substantial amount of data in a complex experimental design, the kind of data many researchers produce in laboratories. Mainframe statistics packages such as SPSS (and recent updates such as SCSS), BMDP, MINITAB, and SAS have been used for this purpose. Some microcomputer statistic programs have capabilities to match some of these well-known mainframe packages.

It has been argued (e.g., Thisted, 1979) that there are advantages to making extensive use of powerful statistics packages (such as SPSS) in the teaching of statistics. However, Castellan (1980) suggested that another approach is to utilize special computer programs that help students become facile with statistical techniques. There are some microcomputer packages that are more specialized toward computer-aided instruction (CAI). The emphasis of these programs is not on analysis of research data; rather, it is on helping students learn statistical concepts or procedures.

Between powerful research analysis tools and CAI software are programs that may be useful to students who need to analyze research data in lab courses or professionals who need to analyze a small amount of data. With this type of program, minimal statistical competence is assumed. Also, the program must be user friendly, and need not handle complex experimental designs.

A summary of how the programs in this review have been categorized is provided in Table 2 . After the many characteristics of the programs have been discussed in more detail, the reasons for this categorization should be apparent. Also, student preferences and the authors' opin- ions about the programs are summarized after a crosscomparison of the features of the programs.

\section{GENERAL PROGRAM FEATURES}

Many of the basic program features are summarized in Table 2. Nearly all of these programs are evolving. Each time a new version is released, problems may be eliminated, error handling may improve, new operating systems may be implemented, or hardware requirements may change. (All of the vendors will receive copies of this manuscript, and I suspect many will correct weaknesses in programs as rapidly as possible.)

The question-answer format is used at times in all of the programs reviewed here; but at other times they differ in their use of menus or command languages. Some of the authors of the software argue that command languages are the most efficient type of operation for users who become familiar with the system. However, these systems are harder to learn, an important consideration for instructional settings and laboratories with a constant turnover of student personnel. Menu systems are much easier to learn. Unfortunately, only Microstat has developed along the lines of powerful word processing systems such as WordStar. WordStar has extensive menus that keep users informed about options and help a new user learn the system. WordStar also allows experienced users to decrease the amount of information displayed in menus or to eliminate the menus completely. Microstat functions similarly. It operates either in menu mode or in a batch mode that uses the same keypresses as the menu mode.

Error conditions, such as dividing by zero, are encountered in all statistical programs. Programs rated "'good" in Table 2 trapped errors, kept the user well informed, and moved to a convenient place in the program at the user's request. Programs rated fair either did not keep

Table 2

General Program Features

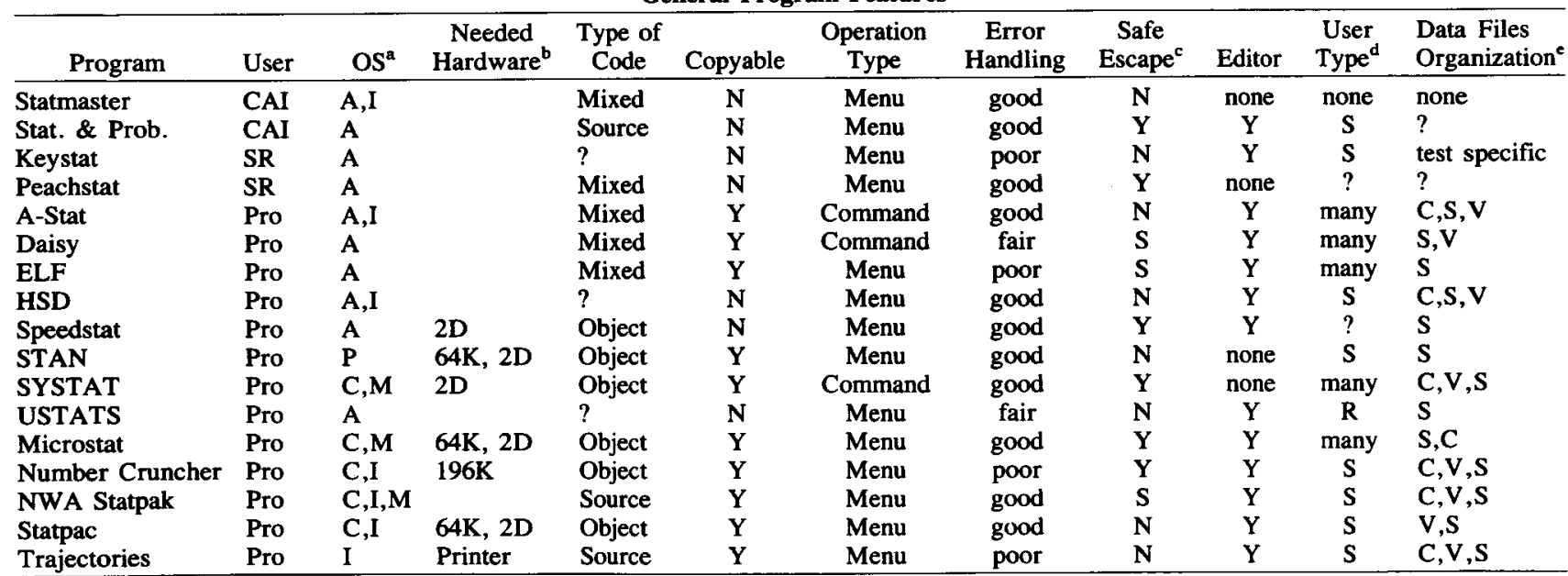

${ }^{\mathrm{a}} \mathrm{A}=$ Apple DOS. $I=I B M P C D O S, C=C P / M, M=M S-D O S . \quad{ }^{\mathrm{b}}$ All programs require 48K RAM, one disk drive, and monitor, except as noted in this column. ${ }^{c} Y=$ yes, $N=$ no, and $S=$ in some places. ${ }^{\mathrm{d}} S=$ sequential text file, $R=$ random text file, many $=$ many file structures such as DIF. ' $\mathrm{e}=$ single file containing all data, $V=$ one variable per file, $C=$ casewise or one subject per file. 
the user well informed or sent the user to some inconvenient place, such as the beginning of the program. Programs rated poor did not trap all errors. Users were abruptly exited to the operating system, a very unfriendly environment for novice computer users.

Safe escape, or the ability to cancel the last few commands or menu choices, can be a highly desirable feature of statistics programs, especially in the educational environment. Student evaluators usually were frustrated by programs that did not allow them safe escape from incorrect input of data or from routines they had accidentally begun.

One way to handle incorrect data input is with an editor. Some programs, such as SYSTAT and USTATS, use system editors rather than program-specific editors. Among those with editors, it was difficult to determine whether editors asking users to specify the array position of data were easier or harder to use than on-screen editors (i.e., what you see is what you get). The student evaluators with average statistics skills had difficulty with on-screen editing that required defining dummy variables. These same students had some difficulty at first in doing the mental arithmetic necessary to keep track of array position. Unfortunately, some programs made students do both tasks (e.g., USTATS) and required complex editing sequences. These programs were very frustrating to students.

Flexible data file organization and/or management is extremely useful for research applications. Some researchers collect data using the computer and store each subject's data independently. Other scientists store all data together in one file. Programs that permit entering data by a single file or by separate subject files can be convenient. It is also useful if the data files contain only data and are written as standard text files. This permits researchers to write files, during computer experiments, that can be read by the statistics program without using intermediate transform programs.

\section{DOCUMENTATION}

Among the programs reviewed here that are either for CAI or student research, only Statmaster must be used with a manual (or workbook). The others are so user friendly that a manual is not needed. However, most of the professional packages must be used with a manual. Without a manual, time may be wasted trying to match an analysis to a set of data. Truly complete, well-organized manuals (i.e., specifications of program limitations, formulas, references, and appropriate examples or tutorials) are not common in statistical documentation (see Table 3). For example, none of the programs reviewed here supplied information describing how probabilities were obtained (table lookup, approximation, etc.).

\section{PROGRAM CAPABILITY}

Since ANOVA is a very common statistical procedure used to analyze data in many publications and is taught in most undergraduate degree programs, extensive evaluation was made of each program's ANOVA capabilities. The results are summarized in Tables 4 and 5 . Individuals interested in regression procedures should refer to the review by Carpenter et al. (1984) and the benchmarks in Lachenbruch (1983) and Longley (1967).

One of the most important features of program output is accuracy. Instructional packages should compute the same answers as hand calculators and other programs. For psychology research, accuracy is even more important. Table 5 shows the accuracy of analysis of variance output in terms of the maximum number of significant digits in the input data. Output was considered inaccurate if any value in the ANOVA table was inaccurate by more than +1 at the least significant digit defined by input. Note that the values reported in Table 5 are generally much lower than the values reported by vendors. I suspect that most vendors report the number-of-digits accuracy in data,

Table 3

Documentation of Programs

\begin{tabular}{|c|c|c|c|c|c|c|c|c|c|}
\hline Program & $\begin{array}{l}\text { Table of } \\
\text { Contents }\end{array}$ & Index & Glossary & $\begin{array}{l}\text { Summary } \\
\text { Card/Page }\end{array}$ & $\begin{array}{l}\text { Number } \\
\text { of Pages }\end{array}$ & Page Size & $\begin{array}{c}\text { Examples/ } \\
\text { Tutorial }\end{array}$ & Formulas & $\begin{array}{c}\text { Technical } \\
\text { References }\end{array}$ \\
\hline Statmaster & $\mathrm{Y}$ & $\mathbf{N}$ & $\mathbf{N}$ & $\mathrm{Y}$ & 216 & $7.5^{\prime \prime} \times 9.5^{\prime \prime}$ & many & $\mathbf{Y}$ & none \\
\hline Stat. \& Prob. & $\mathbf{N}$ & $\mathbf{N}$ & $\mathbf{N}$ & $\mathbf{N}$ & $45^{\mathrm{a}}$ & $8.5^{\prime \prime} \times 11^{\prime \prime}$ & many & some & 8(ANOVA) \\
\hline Keystat & $\mathbf{N}$ & $\mathbf{N}$ & $\mathbf{N}$ & $\mathbf{N}$ & 10 & $5.5^{\prime \prime} \times 7.25^{\prime \prime}$ & none & 1 & none \\
\hline Peachstat & $\mathbf{Y}$ & $\mathbf{N}$ & $\mathbf{N}$ & $\mathbf{N}$ & 12 & $5.5^{\prime \prime} \times 8.5^{\prime \prime}$ & none & none & none \\
\hline A-Stat & $\mathbf{Y}$ & $\mathbf{N}$ & $\mathbf{N}$ & $\mathbf{Y}$ & 140 & $8.5^{\prime \prime} \times 11^{\prime \prime}$ & none & none & 5 \\
\hline Daisy & $\mathbf{Y}$ & $\mathbf{Y}$ & $\mathbf{N}$ & $\mathbf{Y}$ & 262 & $5.5^{\prime \prime} \times 8.5^{\prime \prime}$ & many & some & none \\
\hline ELF & $\overline{\mathbf{Y}}$ & $\mathbf{Y}$ & $\mathbf{N}$ & $\mathbf{N}$ & 122 & $8.5^{\prime \prime} \times 11^{\prime \prime}$ & many & none & many \\
\hline HSD & $\mathrm{N}$ & $\mathbf{N}$ & $\mathbf{N}$ & $\mathbf{N}$ & 54 & $6.5^{\prime \prime} \times 9.25^{\prime \prime}$ & some & none & 5 \\
\hline Speedstat & $\mathbf{Y}$ & $\mathbf{Y}$ & $\mathbf{Y}$ & $\mathbf{N}$ & $198(v 1)$ & $5.5^{\prime \prime} \times 8.5^{\prime \prime}$ & many & yes & $1(\mathrm{v} 1), 10(\mathrm{v} 2)$ \\
\hline STAN & $\mathbf{Y}$ & $\mathbf{N}$ & $\mathbf{N}$ & $\mathbf{N}$ & 103 & $8.5^{\prime \prime} \times 11^{\prime \prime}$ & many & none & 12 \\
\hline SYSTAT & $\mathbf{Y}$ & $\mathbf{Y}$ & $\mathbf{N}$ & $\mathbf{Y}$ & 249 & $6.5^{\prime \prime} \times 8.5^{\prime \prime}$ & many & none & 93 \\
\hline USTATS & short & $\mathbf{Y}$ & $\mathbf{N}$ & $\mathbf{Y}$ & 77 & $6^{\prime \prime} \times 8.5^{\prime \prime}$ & some & none & 5 \\
\hline Microstat & $\mathbf{Y}$ & $\mathbf{Y}$ & $\mathbf{N}$ & $\mathbf{N}$ & 157 & $7.5^{\prime \prime} \times 8^{\prime \prime}$ & many & yes & 6 \\
\hline Number Cruncher & $\mathbf{Y}$ & $\mathbf{Y}$ & $\mathbf{N}$ & $\mathbf{N}$ & 236 & $5.5^{\prime \prime} \times 8.75^{\prime \prime}$ & many & none & 19 \\
\hline NWA Statpak & $\mathbf{Y}$ & $\mathbf{Y}$ & $\mathbf{N}$ & $\mathbf{N}$ & 379 & $8.5^{\prime \prime} \times 11^{\prime \prime}$ & many & most & none \\
\hline Statpac & short & $\mathbf{N}$ & $\mathbf{N}$ & $\mathbf{N}$ & 155 & $8.5^{\prime \prime} \times 11^{\prime \prime}$ & many & yes & 14 \\
\hline Trajectories & $Y$ & $\mathbf{Y}$ & $\mathbf{N}$ & $\mathbf{N}$ & 67 & $8.5^{\prime \prime} \times 11^{\prime \prime}$ & some & none & 16 \\
\hline
\end{tabular}

${ }^{a}$ Each of the diskettes has a separate manual. 
Table 4

Analysis of Variance Design Capabilities

\begin{tabular}{|c|c|c|c|}
\hline \multirow[b]{2}{*}{ Program } & \multirow[b]{2}{*}{ Limits on I.V. $\mathrm{s}^{\mathrm{a}}$} & \multicolumn{2}{|c|}{ Limits on D.V.s } \\
\hline & & No. of Data & Unequal $\mathbf{N}^{\mathbf{b}}$ \\
\hline Statmaster & 2B & \multicolumn{2}{|c|}{ not user controlled } \\
\hline Stat. \& Prob. & IB (5 levels) & 30 per cell & unweighted \\
\hline Keystat & 1B \& 1W (9 levels) & 50 per cell & unweighted \\
\hline Peachstat & 1B (2 levels) & $?$ & unweighted \\
\hline A-Stat & 1B \& IW (8 levels) & 1 disk & unweighted \\
\hline Daisy & $1 B$ or $1 W$ & 4000 data & not allowed \\
\hline ELF & 2B & many disks & unweighted \\
\hline HSD & $5(B \& W)(120$ cells $)$ & 1200 data & unweighted \\
\hline Speedstat & & & \\
\hline STAN & dummy variables ${ }^{c}$ & 1 disk & least sq \\
\hline SYSTAT & dummy variables ${ }^{c}$ & 1 disk & least sq \\
\hline USTATS & 4(B \& W) (8 levels) & 1650 data & unweighted \\
\hline Microstat & $2 B$ or $1 B \& 1 W$ & 1 disk & not allowed \\
\hline Number Cruncher & $4 B$ or $1 W \& 1 B$ & 32000 S's & not allowed \\
\hline NWA Statpak & 3(B \& W) & 5000 data & unweighted ${ }^{d}$ \\
\hline Statpac & 2(B \& W) & 1 disk & unweighted \\
\hline Trajectories & $1 \mathrm{~B}$ or $1 \mathrm{~W}$ & 4000 data & unweighted $^{d}$ \\
\hline
\end{tabular}

not in output following computations. The tests used here are the most rigorous tests of accuracy of which I am aware; however, they probably overestimate the true program accuracy. These tests used only 18-81 datum. Small errors can accumulate with many data. For large data sets, the accuracy is undoubtedly lower than for the values given in Table 5.

As one of my colleagues noted, the results of the accuracy tests suggest that many of these programs are worthless for analyzing research data. This suggests that mainframe packages may be preferable. To examine this possibility, accuracy tests, using the same data sets, were attempted by students on MINITAB, SCSS, SPSSx, and BMDP using our campus VAX mainframe. Students learned how to use MINITAB, but it was only accurate to two digits in the ANOVA table. For many other statistics, it was accurate to seven digits. None of the five students who attempted to run SCSS or SPSSx could figure out how to do an ANOVA. Three students tried to run BMDP, but none was successful. The first author checked BMDP and found that it had at least seven digits of accuracy.

\section{COMPARISON OF PACKAGES}

\section{CAI}

All of the students (five) who used both Statmaster and COMPress's Statistics and Probability by Trumbo preferred the COMPress program. This ANOVA package was preferred because of three great strengths: The explanations (especially in the tutorial) were really helpful, the package allowed students to enter data from their textbooks, and the program permitted safe escape. None of the students was tested for knowledge after having used these programs. Also, these programs differed somewhat in content. Both were rated as very good by students.
Some students enter statistics courses with weak algebra skills or lack other prerequisites. There are other CAI programs, such as Detmer and Smullen's (1981) Algebra Drill and Practice I, that can help students develop or sharpen these skills.

\section{Student Research}

The five students who used both Keystat and Peachtree statistics preferred Keystat. This was surprising because

Table 5

Output of Programs

\begin{tabular}{|c|c|c|c|c|}
\hline \multirow[b]{2}{*}{ Program } & \multicolumn{2}{|c|}{ Good Layout } & \multirow{2}{*}{$\begin{array}{l}\text { Statistics } \\
\text { Missing }^{\text {a }}\end{array}$} & \multirow[b]{2}{*}{ Accuracy } \\
\hline & CRT & Paper & & \\
\hline Statmaster & $\mathbf{Y}$ & & RS & \\
\hline Stat. \& Prob. & $\mathbf{Y}$ & & none & $4^{b}$ \\
\hline Keystat & $\mathbf{Y}$ & $\mathbf{Y}$ & RS & 4 \\
\hline Peachstat & $\mathbf{Y}$ & $\mathbf{Y}$ & RS,SS,MS,p & 3 \\
\hline A-Stat & $\mathbf{N}$ & $\mathbf{N}$ & RS,p & 4 \\
\hline Daisy & $\mathbf{S}$ & $\mathbf{S}$ & $\mathrm{RS}, \mathrm{p}$ & $4^{\mathrm{c}}$ \\
\hline ELF & $\mathbf{N}$ & $\mathbf{N}^{\mathbf{e}}$ & $R S, p^{d}$ & 4 \\
\hline HSD & $\mathbf{Y}$ & $\mathrm{Y}$ & RS & 4 \\
\hline Speedstat & $\mathbf{S}$ & $\mathbf{Y}$ & & \\
\hline STAN & $\mathrm{Y}$ & $\mathbf{N}$ & RS,F & 6 \\
\hline SYSTAT & $\mathbf{Y}$ & $\mathrm{Y}$ & RS & $6^{\mathrm{f}}$ \\
\hline USTATS & $\mathbf{S}$ & $\mathrm{Y}$ & RS & 2 \\
\hline Microstat & $\mathbf{Y}$ & $\mathrm{Y}$ & RS & $?$ \\
\hline Number Cruncher & $\mathbf{S}$ & $S$ & RS & 6 \\
\hline NWA Statpak & $\mathbf{Y}$ & $\mathbf{Y}$ & $R S, p^{d}$ & $3^{\mathrm{c}}$ \\
\hline Statpac & $\mathbf{Y}$ & $\mathbf{Y}$ & RS & 8 \\
\hline Trajectories & $\mathrm{Y}$ & $\mathbf{Y}$ & $R S, p^{d}$ & 3 \\
\hline
\end{tabular}

${ }^{a} A$ complete output for an analysis of variance was defined as $R S$ (raw squares), SS (sums of squares), df (degrees of freedom), MS (mean squares), $F$ (Fisher's $F$ statistic), and $p$, or level of significance. ' bimits input to -10000 to 10000 so no accuracy problems occur. 'Much greater for descriptive statistics. ${ }^{\mathrm{d}}$ Level of significance $(p)$ is available from another program on disk. 'Printer output would be good except that program bugs caused difficulty. ${ }^{\mathrm{f}}$ The program may be even more accurate, but the ANOVA table became unreadable when 6 and 7-digit numbers were used. 
Keystat does not have safe escape and has poor error handling. However, students found Keystat very easy to use and quite powerful. Keystat contains a help program to assist students in finding the right analysis, and it can compute the following statistics: descriptive statistics, chisquare goodness of fit and contingency, $z$ tests, $t$ tests, Mann-Whitney U, sign test, Wilcoxen, ANOVA, KruskalWallis, Friedman, simple regression and correlation, and more. All this costs only $\$ 10$ ! On the other hand, Peachtree statistics can compute descriptive statistics, chi-square contingency, $t$ tests, and correlation coefficients.

\section{Professional Packages}

Most students were able to use at least some of the professional packages, even with no assistance. This was not true for any of the mainframe packages except MINITAB. After students had used several other packages, they were able to make better progress with the difficult micro packages and the mainframe packages. This suggests that there may be value in introducing difficult-to-use packages late in an undergraduate course, after students have used simpler packages.

There are strengths and weaknesses associated with each of the professional programs. The range of procedures and important strengths and weaknesses are described below.

A-STAT. This program was designed primarily for market researchers. As a result, it has powerful correlation and regression capabilities, as well as flexible file handling. Its computational procedures are: contingency table statistics, factor analysis, correlation, regression, $t$ tests, and simple ANOVA. Data entry is easy, but editing is more difficult. Students disliked this package because it was difficult to use and was slow. However, it does permit batch mode operation. A user can request that the program run a sequence of commands without the user's having to type in each command after the last has been completed.

Daisy. This package contains many routines: descriptive statistics, measures of association, contingency tables, correlations, partial correlations, nonparametric correlations, regression, ANOVA, $t$ tests, Mann-Whitney U, Wilcoxen, Friedman, and others. However, its power is not great within any of the routines. Perhaps Daisy would be best classified as the most powerful student research program reviewed here.

ELF. Some students had a great deal of difficulty with this package. This is a reflection of both the type of manual provided with ELF and the power of the package. It can calculate: contingency table statistics, correlations, discriminant functions, factor analyses, stepwise regressions, $t$ tests, and ANOVA. Its inability to handle within-subjects variables in the ANOVA is a major weakness. Also, a number of bugs were discovered during testing. The most severe problem occurred when more than two independent groups were run in the one-way ANOVA; only a small fraction of the ANOVA table is printed. This program's great strength is its ability to use multiple disk data files, but unfortunately this power may be rarely usable because the digits of accuracy are only moderate (see Table 5).

HSD ANOVA. This package is summarized relatively well in Tables 4 and 5 because it is limited to ANOVA. Its combined flexibility and power concerning the independent variables is the best among the microcomputer packages reviewed. More digits of accuracy would improve the program, as would a better, more flexible file handler. For example, 20 separate subject files cannot be combined to run a within-subjects design. Other packages are also available from HSD, including descriptive statistics, regression, correlation, nonparametrics, data graphing, and a student package (which unfortunately was not included in this review). There are two problems with the collection. First, data files are not completely compatible across programs. Second, the combined cost makes this one of the most expensive packages available ( $\$ 650$ plus student package).

Speedstat. Although Speedstat does not yet permit analysis of a wide variety of designs and problems (an ANOVA package and a time-series package are in development), it does a very professional job with the procedures it computes. Volume 1 computes very complete descriptions of the frequency distribution of one variable and contingency tables. Volume 2 computes ordinal and interval scale correlations, stepwise regressions, and other regressions. The package has a special procedure for defining data so that the user is made clearly aware of the accuracy of the program and all output will be accurate. The combination of unique input and complex, thorough output produces a poor instructional package, but a good research tool if the package computes the kind of statistics one needs.

STAN. This package is the only one reviewed that was written in the Pascal operating environment. This environment provides a good on-screen editor and a file management system. STAN is a relatively powerful package that computes with greater accuracy than most of the other packages reviewed here. It is capable of computing the full range of univariate linear model statistics, creating graphical displays of some results, and integrating the results into documents using a word processor. The program is not easy to use: The user must have some knowledge of the Pascal-Apple environment, as well as of linear models, since the manual assumes knowledge of both. In fact, the major weakness of this package is probably the manual, which does not provide abundant examples or many aids to the user. As a result, students were unable to use this package.

SYSTAT. Students found SYSTAT difficult to use because of the linear model format and the non-user friendly style of program flow. Neither of these problems creates difficulty for a professional who is familiar with linear models. The program uses a general multivariate linear model approach to problem solving. As a result, it can be used to analyze a wide variety of designs. Routines include: multiple regression, canonical correlation, 
ANOVA, ANCOVA, MANOVA, profile analysis, principle components, factor analysis, and multidimensional scaling. The program can also handle contingency tables and provides descriptive statistics.

USTATS. This package calculates a variety of statistics: descriptive statistics, $t$ tests, ANOVAs, post hoc comparisons, correlations, regressions, and partial correlations. It was strongly criticized by students because the editor is too cumbersome. Furthermore, the accuracy of this program was the worst of any package tested. Although these problems are substantial, this is the first version of USTATS. Later versions may be greatly improved.

Microstat. Microstat is one of the best packages. It permits batch mode as well as interactive menus. Data entry and editing are much easier than most other professional packages. The program calculates a variety of statistics: descriptive statistics, frequency distributions, $t$ tests, simple ANOVAs, correlations, multiple and stepwise regressions, an excellent variety of nonparametric tests (including Fisher's exact test), contingency tables, and some probability distributions. This may be the best package for providing students their first encounter with a professional package. It is easy to use and covers a wide enough range of statistical procedures to make it useful in the graduate and undergraduate curriculum. The only weakness is the rather restrictive limits on some procedures. However, I was unable to complete accuracy testing on this program. Carpenter et al. (1984) found the regression programs to be extremely accurate.

Number Cruncher. This program has a good data file handler and calculates a diverse array of statistics: descriptive statistics, contingency table statistics, histograms, discriminant analysis, multiple regression, bivariate regression and correlation, ANOVA, classical forecasting methods (which can be used to analyze some $\mathbf{N}=1 \mathrm{de}-$ signs), and a large number of nonparametric tests. The only two weaknesses of the program are the difficult-touse keyboard data entry and editing and the occasionally weak error handling.

NWA Statpak. Overall, students rated this as one of the best professional packages. It is very professional and powerful, with an excellent manual. The following statistics can be computed: probabilities (including Bayes theorem), distribution functions (including Gamma and log normal), Fourier analysis, multiple linear regression, $t$ tests, Pearson correlation, a wide variety of nonparametrics, ANOVAs, and more. The only blemish on this otherwise impressive package is accuracy for ANOVA. Since NWA has already designed regression in double precision, perhaps the same will be done for ANOVA.

Statpac. Statpac is a very good batch-oriented package. It calculates many of the most used statistics: descriptive statistics, frequency distributions, contingency tables, regression, correlation, multiple regression, and simple ANOVA. It has the most flexible data entry (three different systems) and editing procedures of any of the packages reviewed. It is also the most accurate computationally. File handling is not ideal. (I could not find a way to combine separate subject files, a desirable feature for the analysis of many psychology experiments.)

Trajectories. This package computes the following statistics: descriptive statistics, histograms, frequency distributions, contingency table statistics, regression (several models, including multiple), ordinal and interval scale correlation coefficients, $t$ tests, simple ANOVAs, factor analysis, and principle components. Editing is particularly inefficient, but file handling is well done. This is the only package that has a hardbound manual, a feature that clearly moves this package out of the price range of most students.

\section{CONCLUSION}

There are some very good statistical packages available. The micro packages are generally easier to learn and use than the mainframe packages and are not necessarily less accurate. Those designed for students are particularly easy to use and appear to be very useful both for teaching statistical concepts and analyzing relatively simple sets of data. The variety among professional packages is substantial. This is important because the differences in statistical needs of professionals is substantial.

\section{REFERENCES}

Academic Computer Center of Gettysburg College. (1984). Computing in undergraduate psychology: A practicum software guide. Gettysburg, PA: Gettysburg College.

BUTLER, D. L. (1984, June). Using computers in instruction of psychology in higher education: Interests and barriers. Paper presented at the National Educational Computing Conference, Dayton, $\mathrm{OH}$.

Butler, D. L., \& KRING, A. M. (1984). Survey on present and potential instructional use of computers in psychology. Behavior Research Methods, Instruments, \& Computers, 16, 180-182.

Carpenter, J., Deloria, D., \& Morganstein, D. (1984). Statistical software for microcomputers. BYTE, 9(4), 234-264.

Castellan, N. J., JR. (1980). The use of matrix manipulation programs in teaching statistical methods. Behavior Research Methods \& Instrumentation, 12, 172-177.

Cline, H. F. (1972, May). Social science computing. Paper presented at the Spring Joint Computer Conference of the American Federation of Information Processing Societies, Anaheim, CA.

DetMer, R. C., \& SMULLEN, C. W. (1981). Algebra drill and practice $I$ and II [Computer program]. Iowa City, IA: CONDUIT.

EAMON, D. B. (1983). Microcomputer programs for instruction in psychology: A sampler. Collegiate Microcomputer, 1, 11-18.

FrancIS, I. (1983). A survey of statistical software. Computational Statistics and Data Analysis, 1, 17-27.

Kincaid, J. P., Fishburne, R. P., Rogers, R. L., \& Chissom, B. S. (1975). Derivation of new readability formulas (Automated Readability Index, Fog Count, and Flesch Reading Ease Formula) for Navy Personnel (Report No. 8-75). Washington, DC: Naval Training Command Research Branch.

LACHENBRUCH, P. A. (1983). Statistical programs for microcomputers. BYTE, 8(11), 560-570.

LONGLEY, J. W. (1967). An appraisal of least squares programs for the electronic computer from the point of view of the user. Journal of the American Statistical Association, 62, 819-841.

THisted, R. A. (1979). Teaching statistical computing using computer packages. American Statistician, 33, 27-35.

WILsoN, S. R. (1983). Benchmark data sets for the flexible evaluation of statistical software. Computational Statistics and Data Analysis, 1, 29-39. 